This item was submitted to Loughborough's Research Repository by the author.

Items in Figshare are protected by copyright, with all rights reserved, unless otherwise indicated.

\title{
Editorial: Designing for transitions
}

PLEASE CITE THE PUBLISHED VERSION

http://www.drs2018limerick.org/participation/proceedings

\section{PUBLISHER}

(c) The Authors. Published by the Design Research Society

\section{VERSION}

VoR (Version of Record)

\section{PUBLISHER STATEMENT}

This work is made available according to the conditions of the Creative Commons Attribution-NonCommercialShareAlike 4.0 International (CC BY-NC-SA 4.0) licence. Full details of this licence are available at: http://creativecommons.org/licenses/by-nc-sa/4.0/

\section{LICENCE}

CC BY-NC-SA 4.0

\section{REPOSITORY RECORD}

Boehnert, Joanna, Dan Lockton, and Ingrid Mulder. 2019. "Editorial: Designing for Transitions”. figshare. https://hdl.handle.net/2134/35083. 


\title{
Editorial: Designing for Transitions
}

\author{
BOEHNERT, Joannaa ${ }^{a}$ LOCKTON, Dan $^{\mathrm{b}}$ and MULDER, Ingrid ${ }^{\mathrm{c}}$

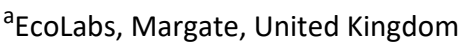 \\ ${ }^{\mathrm{b}}$ Imaginaries Lab, School of Design, Carnegie Mellon University, Pittsburgh, PA, United States \\ ${ }^{\mathrm{C}}$ Department of industrial Design, Delft University of Technology, Delft, Netherlands
}

doi: $10.21606 / \mathrm{dma} .2017 . X X X$

\begin{abstract}
"Transition Design acknowledges that we are living in 'transitional times'. It takes as its central premise the need for societal transitions to more sustainable futures and argues that design has a key role to play in these transitions. It applies an understanding of the interconnectedness of social, economic, political and natural systems to address problems at all levels of spatiotemporal scale in ways that improve quality of life. Transition Design advocates the reconception of entire lifestyles, with the aim of making them more place-based, convivial and participatory and harmonizing them with the natural environment" (Irwin et al 2015).
\end{abstract}

The Designing for Transitions track at DRS 2018 encompasses emerging approaches to design research at the intersection of sustainable design and sociotechnical systems theory. Exemplary are the growing international research communities explicitly centred around Transition Design (e.g. Irwin et al 2015) and Systemic Design (e.g. Sevaldson 2017), aiming to strengthen the role of design in the context of societal challenges. Whether considered in terms of everyday social practices, at a community scale or at the level of global challenges, a framing around designing for transitions brings together considerations of temporality, futures, different types of literacies, participation, social innovation, human needs, and interconnectedness; designing for transitions involves designing how transitions are conceived, enacted, governed and managed.

Our aim at DRS is for the track to build bridges between scholars and designers who work on transition in design, whether their work is explicitly framed in terms of transitions, or whether they encompass expertise and framings which take a broader view of design for social sustainability. The selection of ten full papers on designing for transitions from the 33 submissions to the track provide a window onto a range of diverse current work from researchers with different disciplinary specialities, from social innovation to futures to energy use practices-but all also strongly congruent with the wider theme of DRS 2018, 'Catalyst'. 
The first session clusters five papers that explore 'Future Visioning and Worldviews in Transition' recognising the importance of exploring narratives, mindsets, and visions of different possibilities and alternatives in considering designing for transitions. In the first paper (Hesselgren et al 2018), authors Mia Hesselgren, Elina Eriksson, Josefin Wangel and Loove Broms look at future images of energy transitions with newly designed tools to initiate dialogues and reflections for the future. The second paper is a theoretical reflection on the myths of modernity by Renata M. Leitão. The paper (Leitão 2018) considers myths that are hindering the transformation of our ways of thinking and conditions that will enable new epistemologies to emerge. The third paper (Srivastava and Culén 2018) investigates pathways for decreased consumption amongst millennials. Authors Swati Srivastava and Alma Leora Culén describe Zygo, a future service based on the second-hand marketplace. The fourth paper entitled 'A Vocabulary for Visions in Designing for Transitions' by Dan Lockton and Stuart Candy considers a set of concepts relating particularly to vision in designing for transitions by building on perspectives and projects from other fields (Lockton and Candy 2018). The final paper in this first session is by Jonas Fritsch, 'Affective Interaction Design at the End of the World'. This paper (Fritsch 2018) proposes a rethinking of affect in $\mathrm{HCl}$ and interaction design based on recent theoretical advances in cultural and critical theory, especially affective attachments on a macro-level.

Our second session stresses 'The Practice of Transition Design', through both papers reporting on practical cases, and more theoretical contributions to the analysis of practice in transition contexts. Terry Irwin kicks off, outlining an emerging Transition Design approach for addressing 'wicked' problems (such as climate change, loss of biodiversity, crime, poverty, and pollution) and catalysing societal transitions toward more sustainable and desirable futures, including describing how Transition Design is being tested on a community based project (Irwin 2018). Next, Stacie Rohrbach and Molly Wright Steenson examine teaching and learning in Transition Design, creating a theoretical basis that informs the practice of transition design, outlines methods and tools and proposes opportunities for development (Rohrbach and Steenson 2018). İil Gaziulusoy and Elif Erdoğan Öztekin's paper 'Design as a Catalyst for Sustainability Transitions' contributes a literature review on theories of sustainability transitions and design, also linking very clearly to DRS 2018's overall theme of examining design as a catalyst for change (Gaziulusoy and Erdoğan Öztekin 2018). The fourth paper, entitled 'Catalysing pathway creation for transition governance' by Sampsa Hyysalo, Sofi Perikangas, Tatu Marttila, and Karoliina Auvinen, reviews transition management for catalysing vision building, experimentation and pathway construction for sustainability transitions in a Finnish energy context (Hyysalo et al 2018). Our final presenters, Niti Bhan and Rinku Gajera, examine users in an informal trade ecosystems and the creation of a 'value web' or the value creator's entire value web, as a basis for systemic design interventions (Bhan and Gajera 2018).

While the authors presented visions and practices that demonstrate the critical role of design in the context of societal challenges, they generally stayed on the safe and perhaps 'conventional' side. There is not much explicitly political in these papers. What do we not see represented here? From our perspective as track chairs-drawing on our own research areas as well as others' - we stress the need for an increasing focus on power, politics and the political economy of design for transition. Transition Design must engage with politicised issues such as migration, decoloniality, the politics of climate change mitigation (not just adaptation) and other complex and controversial problems. Perhaps the de-politicised nature of these papers (and typically DRS papers in general) reflects the political economy of design research - and those voices who are able to participate in the Design Research Society community? We note the Decolonising Design group's DRS2016 statement: "We strongly believe that design, as a field of study, has systematically failed to address the questions of power that have shaped its own practice" (Ansari et al, 2016). One might argue that design research is insufficiently engaged with the debates in adjacent disciplines and that designers will find it hard create the change to which Transition Design aspires without better theory and practice around the politics of Transition Design. This expanded focus of attention at the intersection of design, the environment and politics has been developed in some depth in recent work of one of the track 
chairs (Boehnert 2018) and in Arturo Escobar's recent publications $(2015,2018)$. Ultimately, Transition Design must engage with the system structures that determine whose interests are served by design.

Transition Design's focus on systemic approaches must be developed in greater depth. With this collection, we see little work which really employs systems thinking or cybernetic ideas beyond fairly basic notions of complexity or simple feedback loops; it seems as though there is a great opportunity here for a deeper systems investigation of transitions in different contexts, including via participatory methods (e.g. Birney et al 2017; Aguirre Ulloa and Paulsen 2017). As the field matures, we will also-hopefully-see more applied case studies of how a Transition Design approach works in practice, complementing the examples we have in this track at present. This might include more attention to the experience of transitions in everyday life - the ways in which the futures of everyday practices might evolve and change, and how design which centres on lived experience can address that (e.g. Scott et al 2011), how changes in agency (mediated by technological change) may trigger changes in social practices (e.g. Kuijer and Giaccardi 2018) and how that might relate to concepts such as commons and commoning (e.g. Onafuwa 2018 ; Morelli et al., 2017) or even situated 'experiments in transition' such as living labs (e.g. Keyson et al 2016) or living 'in prototypes' (e.g. Desjardins and Wakkary 2016).

In keeping with Mulder and Loorbach (2016) a multi-level perspective approach as well as a transition in the design regime itself are needed to bring both the emerging debate and the corresponding practices around 'transition design' forward. Hence, transitions are long-term, complex, and non-linear processes of systemic change, which usually only become visible at societal level over decades. The high level of ambiguity, unstructuredness, and uncertainty, make it hard to plan and design transitions. The role of design is, however, visible in the various niches, experiments and design interventions indicating their proneness to address societal challenges. A key issue is how these niches together can shape the contours of the changing design regime. See for example, De Koning and colleagues (2017) who studied emerging city makers to understand how their design capabilities can enable systemic change through a focus on participatory design. These new types of city makers generally bring value to the cities, however, their value could be enriched through more participatory networks that stimulate crossovers and accelerate the transition towards sustainable futures. Track chair Ingrid Mulder's work on participatory city making, working with communities and co-design of transitions is relevant here (Mulder \& Loorbach 2016). Transition Design is practice linked to Transition Town movements and community activism. Here again power imbalances need to be theorised, and are all too often poorly articulated in design theory.

In this DRS track, we have brought together various niches in design research, and we hope the corresponding debate more widely at DRS 2018, in our track and in the foreseen keynote "Whose Design?" by Sadie Red Wing and Arturo Escobar, but also will enable a better framing of design for transitions, and mature our design repertoire and actions for transitions.

\section{References}

Aguirre Ulloa, M., \& Paulsen, A. (2017). Co-designing with relationships in mind: Introducing relational material mapping. Form Akademisk, 10(1), 1-14.

Ansari, A., Abdulla. D., Canli, E., Keshavarz, M., Kiem, M., Oliveira, P., Prado L., \& Schultz T. (2016) Decolonising Design: Editorial Statement. 27 June 2016. Accessed online: http://www..decolonisingdesign.com/general/2016/editorial/

Bhan, N. \& Gajera, R. (2018). Identifying the User in an Informal Trade Ecosystem. Proceedings of Design Research Society Conference DRS 2018: Catalyst. Limerick, Ireland, 25-28 June 2018. 
Birney, A., Winn, L., Angheloiu, C. \& Davidson, Z. (2017). The School of System Change as a system change endeavour. In: B. Sevaldson (ed.), Proceedings of Relating Systems Thinking and Design (RSD6) 2017 Symposium. Oslo, Norway, October 18-20, 2017.

Boehnert, J. (2018) Design, Ecology, Politics: Toward the Ecocene. London: Bloomsbury Academic, 2018.

De Koning, J., Puerari, E., Mulder, I. \& Loorbach, D. (2017). Ten types of emerging city makers. In: B. Sevaldson (ed.), Proceedings of Relating Systems Thinking and Design (RSD6) 2017 Symposium. Oslo, Norway, October 18-20, 2017.

Desjardins, A. \& Wakkary. R. (2016). Living In A Prototype: A Reconfigured Space. Proceedings of the $2016 \mathrm{CHI}$ Conference on Human Factors in Computing Systems (CHI '16). New York: ACM.

Escobar, A. (2018) Designs for the Pluriverse. Durham and London: Duke University Press: 2018.

Escobar, A. (2015) Transiciones: a space for research and design for transitions to the pluriverse. Design Philosophy Papers, 13(1):13-23.

Fritsch, J. (2018). Affective Interaction Design at the End of the World. Proceedings of Design Research Society Conference DRS 2018: Catalyst. Limerick, Ireland, 25-28 June 2018.

Gaziulusoy, A.I. and Erdoğan Öztekin, E. (2018). Design as a Catalyst for Sustainability Transitions. Proceedings of Design Research Society Conference DRS 2018: Catalyst. Limerick, Ireland, 25-28 June 2018.

Hesselgren, M., Eriksson, E., Wangel, J., \& Broms, L. (2018). Exploring Lost and Found in Future Images of Energy Transitions: Towards a Bridging Practice of Provoking and Affirming Design. Proceedings of Design Research Society Conference DRS 2018: Catalyst. Limerick, Ireland, 25-28 June 2018.

Hyysalo, S., Perikangas, S., Tatu, M., \& Auvinen, K. (2018). Catalysing pathway creation for transition governance. Proceedings of Design Research Society Conference DRS 2018: Catalyst. Limerick, Ireland, 2528 June 2018.

Irwin, T., Kossoff, G., Tonkinwise, C., \& Scupelli, P. (2015). Transition Design: A new area of design research, practice and study that proposes design-led societal transition toward more sustainable futures. Pittsburgh, PA: Carnegie Mellon School of Design.

Irwin, T. (2018). The Emerging Transition Design Approach. Proceedings of Design Research Society Conference DRS 2018: Catalyst. Limerick, Ireland, 25-28 June 2018.

Irwin, T. (ed.) (2018). Cuadernos del Centro de Estudios de Diseño y Comunicación, Special Issue on Transition Design.

Keyson, D., Guerra Santin, O. \& Lockton, D. (2016). Living Labs: Design and Assessment of Sustainable Living. Berlin: Springer.

Kuijer, L. \& Giaccardi, E. (2018). Co-performance: Conceptualizing the Role of Artificial Agency in the Design of Everyday Life. Proceedings of the 2018 CHI Conference on Human Factors in Computing Systems (CHI '18). New York: ACM.

Leitão, R.M. (2018). Recognizing and overcoming the myths of modernity. Proceedings of Design Research Society Conference DRS 2018: Catalyst. Limerick, Ireland, 25-28 June 2018.

Lockton, D. and Candy, S. (2018). A Vocabulary for Visions in Designing for Transitions. Proceedings of Design Research Society Conference DRS 2018: Catalyst. Limerick, Ireland, 25-28 June 2018.

Morelli, N., Mulder, I., Concilio, G., Pedersen, J., Jaskiewicz, T., De Götzen, A. \& Aguilar, M. (2017). Open Data as a New Commons. Empowering citizens to make meaningful use of a new resource.In: Kompatsiaris I. et al. (eds) Internet Science. INSCI 2017. Lecture Notes in Computer Science, vol 10673. Springer, Cham, pp. 212-221. Available online: https://link.springer.com/chapter/10.1007/978-3-319-70284-1_17

Mulder, I. \& Loorbach, D. (2016). Rethinking Design: a critical perspective to embrace societal challenges. In Gideon Kossoff and Ruth Potts (eds), Proceedings of Transition Design Symposium, Devon, UK.

Onafuwa, D. (2018). Design-Enabled Recommoning: Understanding the Impact of Platforms on Contributing to New Commons. PhD dissertation, Carnegie Mellon School of Design.

Rohrbach. S. and Steenson, M.W. (2018). Transition Design: Teaching and Learning. Proceedings of Design Research Society Conference DRS 2018: Catalyst. Limerick, Ireland, 25-28 June 2018.

Scott, K., Bakker, C., \& Quist, J. (2011). Designing change by living change. Design Studies, 30, 279-297

Sevaldson, B. (ed.) (2017). Proceedings of Relating Systems Thinking and Design (RSD6) 2017 Symposium. Oslo, Norway, October 18-20, 2017.

Srivastava, A. and Culén, A.L. (2018). Transition-oriented Futuring: Integrated Design for Decreased Consumption amongst Millennials. Proceedings of Design Research Society Conference DRS 2018: Catalyst. Limerick, Ireland, 25-28 June 2018. 